\title{
Evaluation of Vital Signs' Fluctuations and Behavioral Responses in the Assessment of Pain in Patients With Traumatic Brain Injury
}

atefeh ghanbari ( $\nabla$ at_ghanbrari@gums.ac.ir)

Guilan University of Medical Sciences https://orcid.org/0000-0002-7949-5717

Ezzat Paryad

Guilan University of Medical Sciences

Arefe safati

Guilan University of Medical Sciences

Ehsan Kazemnezhad Leyli

Guilan University of Medical Sciences

Elaheh Parsasalkisari

debresen university of medical sciences

Research article

Keywords: Fluctuations, Traumatic Brain Injury, diastolic blood pressure

Posted Date: October 6th, 2020

DOI: https://doi.org/10.21203/rs.3.rs-80593/v1

License: (a) This work is licensed under a Creative Commons Attribution 4.0 International License. Read Full License 


\section{Abstract}

\section{Background}

Traumatic brain-injured (TBI) patients suffer severe pain. The assessment of behavioral responses and vital signs seems to be necessary for pain detection in these patients, a matter that this study aims to evaluate.

Methods

This cross sectional study uses repeated measures and included ninety-seven TBI patients from Poorsina hospital, Rasht, Iran. Patients' relevant parameters were recorded using demographic checklist, specifications related to the disease, RASS, CPOT, and FPT tools. The data subsequently were entered into SPSS software V. 21 and were analyze using several tests including Bonferroni's inferential test and Greenhouse-Geisser test, multiple analysis regression coefficient and general linear model by GEE method.

Results

The average age of patients was $42.3 \pm 18.2$. The average consciousness level was $9.30 \pm 2.96$. There was significant difference between the painful and non-painful stimulations in heart rate, systolic blood pressure and diastolic blood pressure $(p<0.001)$. Heart rate $(p<0.001, r=0.253)$, number of respiration $(p<0.001, r=0.173)$, systolic $(p=0.002, r=0.128)$ and diastolic $(p<0.001$, $r=0.223$ ) blood pressures had a positive correlation with behavioral responses. However, the arterial oxygen saturation showed a negative correlation with behavioral responses $(p<0.001, r=-0.361)$. Statistical models demonstrated a significant direct relationship between СРОТ with heart rate $(\beta=2.39, p<0.001)$ and both systolic blood pressure $(\beta=1.31, p=0.002)$ and the fluctuations of diastolic blood pressure $(\beta=0.690, p=0.009)$.

\section{Conclusion}

It seems that behavioral responses are appropriate indices for pain detection. However, vital signs are not capable of being considered as proper indexes for pain assessment since they changed during several procedures while remained unchanged in other tests.

\section{Background}

Traumatic brain injury (TBI) is a physiological disorder of brain function due to strike and results in either chronic or acute disruption in brain neurological functions $(1,2)$. Short-term memory loss, change in mental condition immediately after the injury (such as amnesia, anxiety, and wandering), and focal neurological defects are known to be the brain post-traumatic complications (3). TBI is considered one of the main causes of disability worldwide as the number of traumatic brain-injured patients indicates that 200,000 cases need to be hospitalized in the intensive care unit (ICU) each year. Moreover, 1.74 million patients with mild TBI need to be urgently visited by a doctor and cured $(4,5)$.

Pain is the main concern in patients injured with brain trauma since they experience severe pain and it can alter the natural blood flow and finally increase the risk of brain damage $(6,7)$. TBI patients are usually prescribed high dosages of analgesic or nervous blocking agents in order for the risk of brain edema to reduce(8). However, the use of these medicines provides a challenge for pain assessment because high dosages of analgesic medicines (such as sleeping aids and benzodiazepines) decrease patients' responses to the sensory stimulations and nervous blocking agents cause paralysis. On the other hand, the medicines of both groups have no beneficial effects on pain. As a result, the existence of pain cannot be denied in TBI patients, making the assessment of pain crucial in these patients(9).

Overall, the assessment and of pain and its appropriate treatment are known to be the main concerns in ICU because the majority of the patients are unable to articulate their pain. To address this problem, various methods such as the evaluation of vital signs' fluctuations and behavioral responses are applied for pain assessment (10). vital signs' fluctuations are defined as 
any changes in body temperature, respiration, pulse rate, and blood pressure, all of which indicate one's health condition usually regulated by hemostatic and several normal domains $(11,12)$.

The analysis of behavioral responses to pain is another method by which pain can be evaluated in TBI patients admitted to ICU. Pain behavior assessment tool (PBAT), behavioral pain scale (BPS), and critical care pain observation tool (CPOT) are used to analyze behavioral responses, with CPOT as one of the reliable measures (13). Numerous studies have proved the validity of COPT for ICU patients who are unable to self-report their pain (14). Gelinas et al. demonstrated that TBI cases have various facial expressions and psychological parameters compared to other patients (15). In a study conducted by Arbur et al. pain behaviors in critically ill TBI sufferers were described based on their conciseness levels (16). These behaviors included flushing, sudden eye-opening, moaning, and movement of extremities. A study on the identification of the sensitivity and specificity of (CPOT) for intubated patients who experienced bypass heart surgery showed that CPOT is a valuable tool for the assessment of painful procedures (such as suctioning) in ICU patients (17).

ICU TBI cases are usually not able to talk and self-report the intensity of their pain. Moreover, their related behaviors may be invisible or incomprehensible as a result of analgesic and nervous blocking medicines. Therefore, the evaluation of vital signs and behavioral responses seem to be necessary for ICU patients especially when taking contradictions of various studies into consideration $(4,15)$. More research is needed to verify if monitoring for fluctuations in vital signs can assist nurses in this difficult endeavor (18). This study aims to monitor the fluctuations of vital signs and behavioral responses during the evaluation of pain in TBI patients.

\section{Methods}

Population

This is a cross sectional study with repeated measures in which the vital signs' fluctuations have been detected in ninety-seven TBI patients hospitalized at the ICU section of PoorSina hospital, Rasht, Iran. Members of the population were chosen by consecutive sampling method. A sample size of fifty-seven patients was determined using Cochran equation in which confidence level and test's power were considered $95 \%$ and $90 \%$, respectively. Then, five cases for each disturbing variable were added to the sample size according to the eight disturbing variables found in this study. The final population size included ninety-seven patients.

\section{Ethical considerations}

To meet ethical considerations, the purpose of the study was explained to either patients or their companions, making them sure that patients' information will be kept anonymous and be used without their names or any pictures. This study was approved at the ethical committee of Guilan University of Medical Sciences, Rasht, Iran (IR.GUMS.REC-1396.88).

Inclusion criteria

Age $\geq 18$, being hospitalized in ICU following TBI $\geq 24$ hours, GCS $\geq 13$, the consent of the patients or their companions.

\section{Exclusion criteria}

Any kind of injury or any change in peripheral nervous (motor paralysis, spinal cord injury, or taking nervous blocking agents), any background for chronic drug misuse (based on the medical records), delirium (according to medical records), non-available medical information.

\section{Data collection tools}

In this study, data collection tools included demographic characteristics (age, gender, career, education), disease-related condition (detection, GCS, drowsiness level, type and dosage of analgesic and sedative medicines, and the cause, location, and intensity of pain). Drowsiness level was monitored using RASS. To begin with, patients were visited without any involvement and if conscious, the scores $0-4$ were given to them. Unconscious patients were called by researchers and -1 to -3 points were 
considered based on their responses. When no response was observed, their shoulders were shaken and if there was no answer, their sternums were strongly squeezed and an appropriate point from -5 to -4 was recorded.

The severity of pain was detected using СРОT score. This checklist included five categories of facial expression, body movements, muscle stretching, and the ability to talk in non-intubated patients, and adaptation to ventilation. Each behavior had $(0-2)$ scores and the total scores were (0-8). A total score equal to zero was the minimum score and implied "without pain". Scores 1-3 and 4-5 defined mild pain and moderate pain, respectively. The maximum scores (6 and above) belonged to uncontrolled severe pain. the sum of behavioral changes' scores were calculated by CPOT, a standard tool whose validity and reliability are proved in several studies $(19,20)$.

In this study, face pain thermometer (FPT) was used after either painful or non-painful stimuli and was prepared by the researcher. Vital signs' table (including heart rate, blood pressure, arterial blood oxygen, and respiration) was prepared before, during, and after both painful (change in position) and non-painful (non-invasive blood pressure (NIBP)) stimuli.

Data Collection

Patient's vital signs were incessantly monitored. NIBP was induced by filling the cuff when. Patients were visited during the NIBP procedure and the following position change as a non-painful stimulus. The supervision periods of 1 min, 2 mins, and 15 mins were carried out before, during, and after each procedure with total six evaluation items. At first, patients were visited as a baseline (1 $\mathrm{min}$ ) and vital signs, as well as behavioral responses, were recorded by a researcher. The accuracy of the evaluation was checked by the assistance of an expert who was asked to fill the CPOT forms separately. Then, the NIBP procedure was carried out and the patients were visited during the last two minutes and their items were recorded again before the final record after 15 mins.

The ability to self-report was evaluated by directly asking patients without delirium who was able to communicate and had GCS $\geq 13$ so that they would express the existence (yes/no) and the intensity (0-10 points) of their pain. Afterward, they were asked to score their pain using a 10-score pain scale. Following NIBP, the painful test was done and the vital signs were documented at 1 , 2, and 15 mins. Moreover, the ability to self-report was assessed as NIBP test. It has to be mentioned that an expert supervised all stages and filled the CPOT forms separately.

Statistical analysis

The data were entered to SPSS V. 23 software. Qualitative variables were described using frequency and frequency percentage while quantitative variables were presented using mean, standard deviation, maximum, minimum, median, and confidence interval 95\%. Mean, standard deviation, Bonferroni's test, and Greenhouse-Geisser test were used in order to compare behavioral responses before, during, and after both painful and non-painful stimuli. The potential relationships between pain and either behavioral responses or vital signs' fluctuations were evaluated using multilinear regression for studied variables based on the general linear model using GEE method and with the control of disturbing factors. $p<0.05$ was considered as statistically significant.

\section{Results}

The average age of patients was $42.3 \pm 18.2$ years. The number of males was more than females (65.9\%). Most of the patients had a freelance job (68.22\%), and $80.36 \%$ had an academic education. Regarding the characteristics related to disease, the average consciousness level was $9.2 \pm 30.96$, with 4 and 15 as maximum and minimum levels. The majority of the patients were unconscious (3.42\%). The motorcycle accident was the main cause of the damage ( $98.65 \%)$, followed by fall casualties (23.7\%). Damage in the frontal region was observed in most cases $(27.42 \%)$ with high intensity $(24.41 \%)$. Most of the patients did not receive either analgesic $(98.6 \%)$ or sedative $(41.8 \%)$ medicines. The mean drowsiness was $1.67 \pm 2.01$.

The evaluation of patients' ability of self-report and their behavioral responses before, during, and after using painful and nonpainful stimuli showed that $22.7 \%$ of cases felt pain after painful stimulation while $1 \%$ of them had no pain, and $76.3 \%$ were not able to express their pain because of GCS $<13$. Moreover, according to their self- reports after non-painful stimulation, $18.6 \%$ of 
the patients declared pain, $5.3 \%$ stated no pain. On the other hand, a majority of $76.3 \%$ were unable to state their pain (GCS $<13)$ (Table 1).

Table 1. Frequencies of behavioral responses before, during and after non-painful and painful stimuli as well as self- reports in TBI patients. 


\begin{tabular}{|c|c|c|c|c|c|}
\hline Percentage & Number & $\begin{array}{l}\text { The presence of } \\
\text { pain }\end{array}$ & Behavioral responses & & \\
\hline 1 & 1 & Yes & \multirow[t]{4}{*}{ After a painful stimulus } & \multirow[t]{8}{*}{ Self-report } & \\
\hline 22.7 & 22 & No & & & \\
\hline 76.3 & 74 & $13>\mathrm{GCS}$ & & & \\
\hline & & $\begin{array}{l}\text { (unable to self- } \\
\text { report) }\end{array}$ & & & \\
\hline 5.2 & 5 & No & \multirow{4}{*}{$\begin{array}{l}\text { After non-painful } \\
\text { stimulus }\end{array}$} & & \\
\hline 18.6 & 18 & Yes & & & \\
\hline 76.3 & 74 & $13>$ GCS & & & \\
\hline & & $\begin{array}{l}\text { (unable to self- } \\
\text { report) }\end{array}$ & & & \\
\hline 68 & 66 & Without pain & \multirow[t]{4}{*}{ Before } & \multirow{12}{*}{$\begin{array}{l}\text { Non-painful } \\
\text { stimulation }\end{array}$} & Behavioral \\
\hline 28.9 & 28 & Mild pain & & & \\
\hline 0 & 0 & Moderate pain & & & \\
\hline 3.1 & 3 & Severe pain & & & \\
\hline 21.6 & 21 & Without pain & \multirow[t]{4}{*}{ During } & & \\
\hline 52.6 & 51 & Mild pain & & & \\
\hline 17.5 & 17 & Moderate pain & & & \\
\hline 8.2 & 8 & Severe pain & & & \\
\hline 52.6 & 51 & Without pain & \multirow[t]{4}{*}{ After } & & \\
\hline 36.1 & 35 & Mild pain & & & \\
\hline 9.3 & 9 & Moderate pain & & & \\
\hline 2.1 & 2 & Severe pain & & & \\
\hline 59.8 & 58 & Without pain & \multirow[t]{4}{*}{ Before } & \multirow[t]{12}{*}{ Painful stimulation } & \\
\hline 36.1 & 35 & Mild pain & & & \\
\hline 1 & 1 & Moderate pain & & & \\
\hline 3.1 & 3 & Severe pain & & & \\
\hline 3.1 & 3 & Without pain & \multirow[t]{4}{*}{ During } & & \\
\hline 26.8 & 26 & Mild pain & & & \\
\hline 46.4 & 45 & Moderate pain & & & \\
\hline 23.7 & 23 & Severe pain & & & \\
\hline 51.5 & 50 & Without pain & \multirow[t]{4}{*}{ After } & & \\
\hline 35.1 & 34 & Mild pain & & & \\
\hline 10.3 & 10 & Moderate pain & & & \\
\hline 3.1 & 3 & Severe pain & & & \\
\hline
\end{tabular}


MANOVA test showed significant difference between the painful and non-painful stimulations in heart rate, systolic blood pressure and diastolic blood pressure $(p<0.001)$ (Table 2$)$.

Using a non-painful stimulus, there was no significant difference in the number of respirations compared to reference time $(p<$ 0.99). Yet, it significantly differed during and after painful stimulation compared to reference time (before painful stimulus) ( $p<$ 0.001), although no significant difference was seen in arterial oxygen saturation during the assessments compared to reference times $(p<0.05)($ Table 2).

Table 2. Comparison of vital signs' fluctuations and behavioral responses before, during and after painful and non-painful simulations in ICU TBI patients.

\begin{tabular}{|c|c|c|c|c|c|c|c|}
\hline \multirow[b]{2}{*}{$\mathrm{p}$} & \multicolumn{3}{|c|}{ Painful stimulus } & \multicolumn{3}{|c|}{ Non-painful stimulus } & \multirow{2}{*}{$\begin{array}{l}\text { Vital } \\
\text { signs/ } \\
\text { behavioral } \\
\text { Reponses }\end{array}$} \\
\hline & $\begin{array}{l}\text { After } \\
(\text { Mean } \pm S D)\end{array}$ & $\begin{array}{l}\text { During } \\
\text { (Mean } \pm \text { SD) }\end{array}$ & $\begin{array}{l}\text { Before } \\
(\text { Mean } \pm \text { SD) }\end{array}$ & $\begin{array}{l}\text { After } \\
(\text { Mean } \pm \text { SD) }\end{array}$ & $\begin{array}{l}\text { During } \\
\text { (Mean } \pm \text { SD) }\end{array}$ & $\begin{array}{l}\text { Before } \\
\text { (Mean } \pm \text { SD) }\end{array}$ & \\
\hline $\begin{array}{l}* \\
<0.001\end{array}$ & $91.57 \pm 19.90$ & $96.95 \pm 24.43$ & $89.06 \pm 19.47$ & $88.16 \pm 20.63$ & $90.20 \pm 20.29$ & $86.71 \pm 20.38$ & Heart rate \\
\hline- & $* *<0.001$ & $\star \star * 0.001$ & Reference & $\star \star 0.173$ & $* *<0.001$ & Reference & $\mathrm{p}$ \\
\hline$\star 0.160$ & $21.88 \pm 5.17$ & $24.48 \pm 6.40$ & $20.67 \pm 6.03$ & $19.97 \pm 6.67$ & $21.89 \pm 6.94$ & $22.44 \pm 26.55$ & $\begin{array}{l}\text { No of } \\
\text { respiration }\end{array}$ \\
\hline- & $* *<0.001$ & $* *<0.001$ & Reference & $\star \star 0.999$ & $\star \star 0.999$ & Reference & $\mathrm{p}$ \\
\hline $\begin{array}{l}\star \\
<0.001\end{array}$ & $130.23 \pm 16.39$ & $133.79 \pm 16.78$ & $129.04 \pm 17.09$ & $129.12 \pm 15.37$ & $129.59 \pm 16.12$ & $127.18 \pm 16.88$ & $\begin{array}{l}\text { Systolic } \\
\text { blood } \\
\text { pressure }\end{array}$ \\
\hline- & $\star \star 0.999$ & $\star *<0.001$ & Reference & $\star \star 0.398$ & $\star \star 0.051$ & Reference & $\mathrm{p}$ \\
\hline $\begin{array}{l}* \\
<0.001\end{array}$ & $76.12 \pm 10.06$ & $82.05 \pm 9.64$ & $76.99 \pm 9.75$ & $76.37 \pm 8.19$ & $78.15 \pm 16.10$ & $75.60 \pm 12.26$ & $\begin{array}{l}\text { Diastolic } \\
\text { blood } \\
\text { pressure }\end{array}$ \\
\hline- & $\star * 0.999$ & $* *<0.001$ & Reference & $\star \star 0.999$ & $\star \star 0.999$ & Reference & $\mathrm{p}$ \\
\hline$\star 0.284$ & $97.15 \pm 2.08$ & $96.41 \pm 2.06$ & $96.19 \pm 10.04$ & $96.65 \pm 9.49$ & $106.56 \pm 87.06$ & $97.78 \pm 1.72$ & $\begin{array}{l}\text { Arterial } \\
\text { oxygen } \\
\text { saturation }\end{array}$ \\
\hline- & $\star * 0.999$ & $\star \star 0.999$ & Reference & $\star * 0.999$ & $\star \star 0.999$ & Reference & $\mathrm{p}$ \\
\hline $\begin{array}{l}* \\
<0.001\end{array}$ & $1.35 \pm 1.73$ & $1.41 \pm 1.61$ & $0.96 \pm 1.46$ & $1.29 \pm 1.70$ & $2.37 \pm 1.86$ & $0.82 \pm 1.46$ & $\begin{array}{l}\text { Behavioral } \\
\text { responses }\end{array}$ \\
\hline- & $\star \star 0.103$ & $\star *<0.001$ & Reference & $\star \star 0.014$ & $\star \star * 0.001$ & Reference & $\mathrm{p}$ \\
\hline
\end{tabular}

*Greenhouse-Geisser

**Bonferroni's test

As Spearmen's test suggests, there was a significant positive correlation between heart rate $(r=0.253, p<0.001)$, the number of respiration $(p<0.001, r=0.173)$ systolic blood pressure $(p=0.002, r=0.128)$, diastolic blood pressure $(p<0.001, r=0.223)$ and behavioral responses. However, arterial oxygen saturation showed a negative significant correlation with behavioral responding $(p<0.001, r=-0.361)$. Self-report which can only be measure in patients with GCS $>13$ had a significant negative correlation with arterial oxygen saturation $(p<0.001, r=509)$ although no significant correlation was observed with other vital parameters (Table3).

Table 3. The correlation between vital signs' fluctuations and behavioral responses' scores with self-report in ICU TBI patients. 


\begin{tabular}{|c|c|c|c|}
\hline Behavioral responses & Self-report & Vital signs & \\
\hline 0.085 & 0.253 & Spearmen's correlation & \multirow[t]{2}{*}{ Heart rate } \\
\hline 0.573 & 0.000 & $\mathrm{P}$ & \\
\hline-0.127 & 0.173 & Spearmen's correlation & \multirow[t]{2}{*}{ No of respiration } \\
\hline 0.400 & 0.000 & $P$ & \\
\hline 0.052 & 0.128 & Spearmen's correlation & \multirow[t]{2}{*}{ Systolic blood pressure } \\
\hline 0.730 & 0.002 & $\mathrm{P}$ & \\
\hline-0.056 & 0.223 & Spearmen's correlation & \multirow[t]{2}{*}{ Diastolic blood pressure } \\
\hline 0.713 & 0.000 & $\mathrm{P}$ & \\
\hline-0.509 & -0.361 & Spearmen's correlation & \multirow[t]{2}{*}{ Arterial oxygen saturation } \\
\hline 0.000 & 0.000 & $P$ & \\
\hline
\end{tabular}

СРОТ had a statistically significant and direct relationship with heart rate $(\beta=2.39, p<0.001)$ and systolic blood pressure $(\beta=1.31, p=0.002)$, and diastolic blood pressure $(\beta=0.690, p=0.009)$, as general linear model determined. However, there was no significant relationship between СРОT and the number of respiration $(\beta=0.406, p=0.176)$ or arterial oxygen saturation $(\beta=0.191$, $\mathrm{p}=0.831)($ Table 4)

Table 4. The relationship between pain and vital signs' fluctuations having controlled disturbing variables. 


\begin{tabular}{|c|c|c|c|c|c|c|c|c|c|c|}
\hline \multicolumn{2}{|c|}{$\begin{array}{l}\text { Arterial oxygen } \\
\text { saturation }\end{array}$} & \multicolumn{2}{|c|}{$\begin{array}{l}\text { Diastolic blood } \\
\text { pressure }\end{array}$} & \multicolumn{2}{|c|}{$\begin{array}{l}\text { Systolic blood } \\
\text { pressure }\end{array}$} & \multicolumn{2}{|c|}{ No of respiration } & \multicolumn{2}{|c|}{ Heart rate } & \multirow[t]{2}{*}{ Variables } \\
\hline Sig. & $\beta$ & Sig. & $\beta$ & Sig. & $\beta$ & Sig. & $\beta$ & Sig. & $\beta$ & \\
\hline 0.000 & 107.311 & 0.000 & 66.366 & 0.000 & 15.371 & 0.832 & 1.802 & 0.000 & 154.960 & (Intercept) \\
\hline 0.831 & 0.191 & 0.009 & 0.690 & 0.002 & 1.127 & 0.176 & 0.406 & 0.000 & 2.392 & СРОТ \\
\hline 0.420 & -2.800 & 0.219 & 1.259 & 0.277 & 1.565 & 0.258 & 1.318 & 0.225 & 2.090 & $\begin{array}{l}\text { Painful } \\
\text { intervention }\end{array}$ \\
\hline 0.567 & 0.089 & 0.119 & 0.072 & 0.692 & 0.026 & 0.629 & -0.025 & 0.005 & -0.220 & age \\
\hline 0.889 & -0.510 & 0.060 & 2.029 & 0.009 & 3.987 & 0.259 & 1.388 & 0.021 & 4.210 & gender \\
\hline 0.765 & 1.058 & 0.003 & 3.139 & 0.003 & 4.414 & 0.443 & -0.913 & 0.038 & 3.656 & $\begin{array}{l}\text { Education } \\
\text { level }\end{array}$ \\
\hline 0.793 & -0.388 & 0.884 & -0.064 & 0.453 & 0.459 & 0.071 & 0.894 & 0.000 & -4.949 & GCS \\
\hline 0.704 & 2.159 & 0.873 & -0.268 & 0.390 & 2.027 & 0.373 & 1.698 & 0.677 & 1.175 & MCA \\
\hline 0.715 & -2.176 & 0.859 & 0.313 & 0.059 & 4.672 & 0.749 & -0.641 & 0.508 & -1.960 & Fall \\
\hline 0.396 & -3.147 & 0.003 & 3.246 & 0.000 & 8.637 & 0.635 & 0.590 & 0.488 & -1.276 & Frontal \\
\hline 0.894 & 0.475 & 0.011 & -2.691 & 0.024 & -3.327 & 0.408 & 0.990 & 0.001 & 7.332 & Temporal \\
\hline 0.477 & -3.615 & 0.829 & 0.323 & 0.016 & 5.080 & 0.011 & 4.340 & 0.001 & -10.861 & $\begin{array}{l}\text { Damage } \\
\text { severity }\end{array}$ \\
\hline 0.998 & 0.002 & 0.001 & 1.222 & 0.086 & 0.823 & 0.183 & -0.517 & 0.003 & 1.682 & $\begin{array}{l}\text { Drowsiness } \\
\text { level }\end{array}$ \\
\hline 0.213 & 4.479 & 0.001 & -3.830 & 0.000 & -8.338 & 0.342 & -1.148 & 0.001 & -7.550 & $\begin{array}{l}\text { Analgesic } \\
\text { treatment }\end{array}$ \\
\hline 0.863 & -0.783 & 0.656 & -0.596 & 0.475 & -1.342 & 0.110 & -2.435 & 0.016 & -5.431 & $\begin{array}{l}\text { Sedative } \\
\text { treatment }\end{array}$ \\
\hline- & 1319.886 & - & 114.804 & - & 227.073 & - & 148.860 & - & 325.097 & (Scale) \\
\hline
\end{tabular}

\section{Discussion}

This study showed that heart rate is directly related to the painful stimulation compared to before and after using painful stimulus. These results are consistent with those of Aïssaoui et al.(21), Payen et al.(22), and Young et al(23). Our results highlight that heart rate can be considered as a pain indicator in TBI patients since pain activates the sympathetic system, releases epinephrine, and finally increases heart rate in patients laying back at ICU for a long time (22). Therefore, the heart rate can be an appropriate index for the detection of pain in TBI patients.

This study shows that the number of respiration increased significantly during and after painful motivation compared to reference time (before painful stimulus). This suggests that respiration rate may detect the severity of pain in TBI patients because different levels of pain especially chronic pain cause various responses in respiration such as changes in lung's volume as well as respiration rate and depth. The results found by Kapostina et al. were aligned with these outcomes (10).

Systolic and diastolic blood pressure increased only during painful stimulation compared to reference time. In a study by Young et al. a significant increase in blood pressure reported during a painful procedure (change in position) and a non-painful procedure (eye care) (23). However, Li et al. found no significant increase in systolic and diastolic blood pressure when imposing a painful procedure (24). This is why some pain experts do not recommend physiologic parameters such as blood pressure for the detection of pain $(25,26)$. According to the present results, it seems that blood pressure is not capable of being a valuable index for pain detection in TBI patients since it varies in other conditions such as blood volume, blood viscosity, vascular 
elasticity, and peripheral resistance, the status of health muscles, genetic differences, diet, weight, activity level, and emotional status.

Present results regarding the distribution of behavioral responses (before, during, and after using a painful stimulation) in TBI patients showed a significant increase in behavioral responses during a painful stimulation procedure compared to the reference time. Likewise, similar results were found by Roulin et al (14). It should be noted that although behavioral responses proved to increase significantly as a result of both painful and non-painful stimuli, the scores of behavioral responses doubled during a painful stimulus comparing before it had been used. Le et al. declared that TBI patients showed more responses following the change in position or during NIBP (27). Moreover, a study by Joffe et al. demonstrated that CPOT scores were considerably increased when patients were moved compared to the time when they were gently touched (28). Our results showed that behavioral responses may be valuable indicators of pain assessment in TBI patients. Likewise, American nursing society and the society of critical care suggest behavioral responses for pain detection in patients who are not able to express their pain since these responses rely on the individual pain tolerance and usually manifest in appearance and body movements such as squeezing teeth, holding the painful part, bending, moaning, crying, and uneasiness (29).

Furthermore, behavioral responses proved to increase significantly during non-painful stimulus and after non-painful stimulus. In contrast, Kapoustina et al. reported that his most popular response during three assessment related NIBP was neutral. In their study, several reactions including eye-opening and no resistance to non-active non-vocal movement during both painful and nonpainful stimulation procedures were observed equally(10). Moreover, the behaviors in rest condition did not change in response to non-painful procedure and during NIBP, as Lee et al. reported (27). As numerous tools including pain behavioral assessment tool (PBAT), pain behavioral tool( PBS), and critical pain observation tool (CPOT) which is one of the most straightforward methods (13) and use in this study, the inconsistency between their results and our study can be attributed to the instruments and tools used in the detection of behavioral responses.

Unknown background of any underlying disease and lack of patients' background can be considered as the limitations of this study.

\section{Conclusions}

According to the present study, it can be concluded that there is a relationship between behavioral responses or vital signs' fluctuations and pain. Since behavioral responses change in all procedures that were expected to be painful for patients, it can be deduced that these responses may be beneficial indicators for pain. However, vital signs do not seem to be appropriate to be considered as pain indices because several signs fluctuate during some tests while others remained unchangeable. In conclusion, behavioral responses and several vital signs may be promising indicators of pain.

\section{Abbreviations}

TBS: Traumatic brain-injured; ICU: Intensive Care Unit; PBAT: Pain behavior assessment tool ; PBS: Behavioral Pain Scale (BPS); CPOT: Critical Care Pain Observation Tool ;GCS: Glasgow Coma Scale ;RASS:Richmond Agitation and Sedation Scale ;FPT: Face Pain Thermometer ;NIBP: Non-invasive Blood Pressure ;PBAT: Pain Behavioral Assessment Tool

\section{Declarations}

\section{Ethics approval and consent to participate:}

The study was conducted in accordance with the ethical principles and its protocol was approved by the Ethics Committee of Guilan University of Medical Sciences (ethical code: IR.GUMS.REC-1396.88).

Consent for publication: Not applicable

Availability of data and materials: The datasets used and /or analyzed during the current study are available from the corresponding author on reasonable request

Page $10 / 12$ 
Competing interest: Authors declared no conflict of interest.

Funding: The study was funded by the Deputy for Research; Guilan University of Medical Sciences. The funder had no role in the study design, data analysis and interpretation, and writing of the manuscript.

Authors' contribution: GA, PE and SA: the study design; SA, PE and GA: data collection; GA, PE, SA and KE: data analysis; data interpretation and drafting of the manuscript. All authors read and approved the final version of the manuscript.

Acknowledgements: The authors wish to thank all the individuals who helped throughout the study, especially PoorSina hospital and Department of Research and Technology of Guilan University of Medical Sciences, Rasht, Iran

\section{References}

1. Jassam YN, Izzy S, Whalen M, McGavern DB, El Khoury J: Neuroimmunology of traumatic brain injury: time for a paradigm shift. Neuron 2017, 95(6):1246-65. doi:10.1016/j.neuron.2017.07.010.

2. Nguyen R, Fiest KM, McChesney J, Kwon C-S, Jette N, Frolkis AD, et al: The international incidence of traumatic brain injury: a systematic review and meta-analysis. Canadian journal of neurological sciences 2016,43(6):774-85. doi: $10.1017 /$ cjn.2016.290.

3. Vella MA, Crandall ML, Patel MB: Acute management of traumatic brain injury. Surgical Clinics 2017, 97(5):101530.doi: 10.1016/j.suc.2017.06.003

4. Arbour C, Choinière M, Topolovec-Vranic J, Loiselle CG, Gélinas C: Can fluctuations in vital signs be used for pain assessment in critically ill patients with a traumatic brain injury? Pain research and treatment 2014, 2014: doi: 10.1155/2014/175794

5. Fetta J, Starkweather A, Gill JM: Computer-based cognitive rehabilitation interventions for traumatic brain injury: a critical review of the literature. The Journal of neuroscience nursing: journal of the American Association of Neuroscience Nurses 2017, 49(4):235.doi: 10.1155/2014/175794.

6. Hayes JP, Logue MW, Sadeh N, Spielberg JM, Verfaellie M, Hayes SM, et al: Mild traumatic brain injury is associated with reduced cortical thickness in those at risk for Alzheimer's disease. Brain 2017, 140(3):813-25. doi:10.1093/brain/aww344.

7. Roulin M-J, Ramelet A-S: Generating and selecting pain indicators for brain-injured critical care patients. Pain Management Nursing 2015, 16(3):221-32. doi.org/10.1016/j.pmn.2014.06.003

8. Dang B, Chen W, He W, Chen G: Rehabilitation treatment and progress of traumatic brain injury dysfunction. Neural plasticity 2017, 2017. doi: 10.1155/2017/1582182

9. Soliman HM, Vincent JL. Sedative and analgesic practice in the intensive care unit:the results of a European survey. British Journal of Anaesthesia 2001;87(2).186-92.

10. Kapoustina O, Echegaray-Benites C, Gélinas C: Fluctuations in vital signs and behavioural responses of brain surgery patients in the intensive care unit: are they valid indicators of pain? Journal of advanced nursing 2014, 70(11):2562-76. doi.org/10.1111/jan.12409.

11. Lee K, Oh H, Suh Y, Seo W: Patterns and clinical correlates of pain among brain injury patients in critical care assessed with the Critical Care Pain Observation Tool. Pain Management Nursing 2013, 14(4):259-67. doi: 10.1016/j.pmn.2011.05.005.

12. Marehbian J, Muehlschlegel S, Edlow BL, Hinson HE, Hwang DY: Medical management of the severe traumatic brain injury patient. Neurocritical care 2017, 27(3):430-46. doi:10.1007/s12028-017-0408-5.

13. Puntillo KA, Morris AB, Thompson CL, Stanik-Hutt J, White CA, Wild LR: Pain behaviors observed during six common procedures: results from Thunder Project II. Critical care medicine 2004, 32(2):421-

7.doi: 10.1097/01.CCM.0000108875.35298.D2

Page $11 / 12$ 
14. Roulin M-J, Ramelet A-S: Behavioral changes in brain-injured critical care adults with different levels of consciousness during nociceptive stimulation: an observational study. Intensive care medicine 2014, 40(8):1115-23. doi:10.1007/s00134014-3380-y

15. Gélinas $C$, Arbour C: Behavioral and physiologic indicators during a nociceptive procedure in conscious and unconscious mechanically ventilated adults: similar or different? Journal of critical care 2009, 24(4):628. e7-.

e17.doi:: 10.1016/j.jcrc.2009.01.013

16. Arbour C, Choinière M, Topolovec-Vranic J, Loiselle CG, Puntillo K, Gélinas C: Detecting pain in traumatic brain-injured patients with different levels of consciousness during common procedures in the ICU: typical or atypical behaviors? The Clinical journal of pain 2014. 30(11):960-9. doi: 10.1097/ajp.0000000000000061

17. Ghanbari A, Farmanbar R, Kazemnejad E: Sensitivity and specificity of Critical Care Pain Observation Tool used for intubated patients following open-heart surgery. Intensive Care Med 2016, 42(4):618-619.doi: 10.1007/s00134-015-4209-z

18. Boitor M, Richard-Lalonde M, Bérubé $M$ et al: Vital signs fluctuations and their relationship with pain in the brain-injured adult critically ill - A repeated-measures descriptive-correlational study. Intensive \& Critical Care Nursing 2019, 55: doi.org/10.1016/j.iccn.2019.07.002

19. Dale CM, Prendergast V, Gélinas C, Rose L: Validation of The Critical-care Pain Observation Tool (CPOT) for the detection of oral-pharyngeal pain in critically ill adults. J Crit Care 2018, 48:334-338. doi: 10.1016/j.jcrc.2018.09.024.

20. Rijkenberg S,Van der Voort PHJ: Can the critical-care pain observation tool (CPOT) be used to assess pain in delirious ICU patients? J Thorac Dis 2016, 8(5):E285-E287. doi: 10.21037/jtd.2016.03.32

21. Aïssaoui Y ZA, Zekraoui A, Abidi K, Abouqal R: Validation of a behavioral pain scale in critically ill, sedated, and mechanically ventilated patients. Anesthesia \& Analgesia 2005, 101(5):1470-6.doi: 10.1213/01.ANE.0000182331.68722.FF.

22. Payen J-F BO, Bosson J-L, Lagrasta A, Novel E, Deschaux I, et al: Assessing pain in critically ill sedated patients by using a behavioral pain scale. Critical care medicine 2001, 29(12):2258-63. doi: 10.1097/00003246-200112000-00004

23. Young J SJ, Nikoletti S, Shaw T: Use of a Behavioural Pain Scale to assess pain in ventilated, unconscious and/or sedated patients. Intensive and Critical Care Nursing 2006, 22(1):32-9.doi: 10.1016/j.iccn.2005.04.004.

24. Li D MC, Burkhardt D, Puntillo K: Evaluations of physiologic reactivity and reflexive behaviors during noxious procedures in sedated critically ill patients. Journal of Critical Care 2009, 24(3):472 e9- e13.doi: 10.1016/j.jcrc.2008.07.005.

25. Herr K CP, McCaffery M, Manworren R, Merkel S: Pain assessment in the patient unable to self-report: position statement with clinical practice recommendations. Pain Management Nursing 2011, 12(4):230-50.doi:10.1016/j.pmn.2011.10.002.

26. Barr J FG, Puntillo K, Ely EW : Clinical practice guidelines for the management of pain, agitation, and delirium in adult patients in the intensive care unit. Critical Care Medicine 2013, 41(1):263-306.doi: 10.1097/CCM.0b013e3182783b72

27. Lee Q GC, Arbour C, Rodrigue N: Description of behaviors in nonverbal critically ill patients with a traumatic brain injury when exposed to common procedures in the intensive care unit: a pilot study. Pain Management Nursing 2013, 14(4):e251-e61. doi.org/10.5935/0103-507x.20180009

28. Joffe A MB, Boitor M, al. e. Validation of the Critical-Care Pain Observation Tool in brain-injured critically ill adults. Journal of Critical Care 2016, 36(2016):76-80. doi: 10.1016/j.jcrc.2016.05.011

29. Nazari R, Allen KA, Sharif Nia H, Yee BL, Yaghoobzadeh A: Behavioral Pain Indicators in Patients with Traumatic Brain Injury Admitted to an Intensive Care Unit. J Caring Sci 2018, 7(4):197-203. doi: 10.15171/jcs.2018.030 